Received: 21 July 2017

Accepted: 26 October 2017

Published online: 13 November 2017

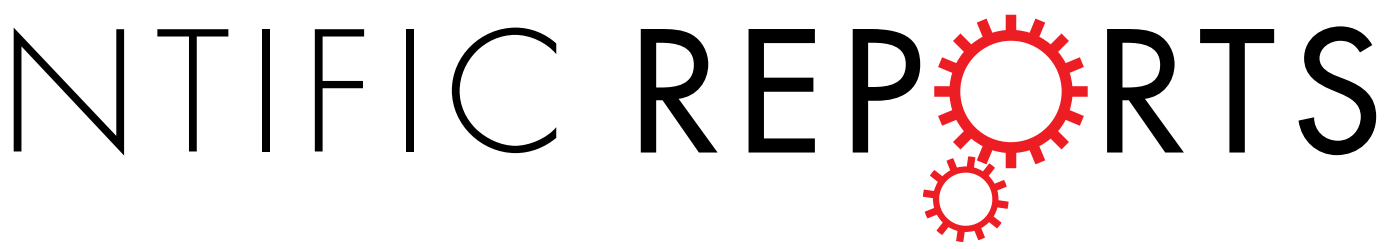

\title{
Effect of soy on bone turn-over markers in men with type 2 diabetes and hypogonadism - a randomised controlled study
}

\section{T. Sathyapalan ${ }^{1}$, M. Aye $\mathbb{1}^{1}$, A. S. Rigby ${ }^{2}$, W. D. Fraser ${ }^{3}$, E. S. Kilpatrick ${ }^{4}$ \& S. L. Atkin $\mathbb{1}^{5}$}

Type 2 diabetes (T2DM) is associated with increased risk of fractures. Soy supplementation has been shown to have a beneficial effect on bone turnover markers (BTM) in postmenopausal women. However, the effect of soy supplementation on BTM in T2DM and particularly in men is unclear. We performed an analysis of a randomized double blind parallel study of 200 men with T2DM treated with soy, either with or without isoflavones. Outcome measures were type I collagen crosslinked beta C-telopeptide ( $(\mathrm{CTX})$, and type 1 procollagen-N-propeptide (P1NP). The men, with a total testosterone $<12 \mathrm{nmol} / \mathrm{L}$, were treated with $15 \mathrm{~g}$ soy protein containing $66 \mathrm{mg}$ of isoflavones (SPI) or $15 \mathrm{~g}$ soy protein alone without isoflavones (SP) daily for three months. There was a 15\% reduction in $\beta C T X$ after three months of SPI compared to SP supplementation. There was no significant difference in P1NP with either SPI or SP supplementation. There was a significant linear correlation between the reduction in $\beta C T X$ in the SPI group with the reduction in $\mathrm{HbAlc}\left(r^{2}=0.42 ; p=0.04\right)$ and HOMA-IR $\left(r^{2}=0.54 ; p=0.02\right)$. Our study indicates that there was a significant reduction in bone resorption following 3 months of SPI supplementation that correlated with an improvement of glycemic control in men with T2DM.

There is substantial epidemiological evidence that people with T2DM has increased risk of fractures ${ }^{1,2}$. This increase in fracture risk occurs despite bone mineral density (BMD) being comparatively higher in those with T2DM than those without. In a meta-analysis, Vestergaard reported an increased Z-score of 0.41 at the spine and 0.27 at the hip associated with $\mathrm{T}_{2} \mathrm{DM}^{2}$. T2DM has been shown to be an independent risk factor for fractures, which is not attributable to increased body mass index (BMI) or other classical osteoporosis risk factors ${ }^{3}$.

Testosterone is anabolic for bone primarily through its aromatization to estrogen in adipose tissue ${ }^{4}$. Low testosterone in the setting of low or inappropriately normal luteinizing hormone and follicle-stimulating hormone is common in the diabetes population and may contribute to impaired bone strength in these men with T2DM .

Production and consumption of soy foods within Western countries have increased dramatically with postulated health benefits including improvement in bone health, especially in women ${ }^{6}$. Habitual intake of soy isoflavones has also been associated with a reduced risk of T2DM and cardiovascular disease (CVD) ${ }^{7}$.

Bone turnover markers (BTMs) are biomarkers for fracture risk that have been used for the evaluation of effects of osteoporosis treatments, and include both bone resorption markers (e.g. type I collagen crosslinked Beta C-telopeptide $(\beta C T X)$ ) and bone formation markers (e.g. type I procollagen-N-propeptide (PINP)). Hypogonadal men with type 2 diabetes have smaller bone size and lower bone turn over ${ }^{8}$. We conducted this analysis to study the effect of soy isoflavone supplementation on BTMs in men with T2DM and low testosterone levels $(<12 \mathrm{nmol} / \mathrm{L})$.

\footnotetext{
${ }^{1}$ Academic Diabetes, Endocrinology and Metabolism, Hull York Medical School, University of Hull, Hull, UK. ${ }^{2}$ Department of Academic Cardiology, University of Hull, Hull, UK. ${ }^{3}$ Norwich Medical School, Faculty of Medicine and Health Sciences, University of East Anglia, Norwich, UK. ${ }^{4}$ Department of Clinical Chemistry, Sidra Medical and Research Center, Doha, Qatar. ${ }^{5}$ Weill Cornell Medical College Qatar, Education City, PO Box 24144, Doha, Qatar. Correspondence and requests for materials should be addressed to T.S. (email: Thozhukat.sathyapalan@hyms. ac.uk)
} 


\section{Research Design and Methods}

This post-hoc analysis included data from men who had participated in a randomized double blind parallel study investigating the effect of soy isoflavones on testosterone concentrations in men with $\mathrm{T}_{2} \mathrm{DM}^{9} .412$ Caucasian male patients with T2DM were screened. 200 men between 45 to 75 years of age with an early morning total testosterone concentrations of less than $12 \mathrm{nmol} / \mathrm{L}$ (normal range $-12-25 \mathrm{nmol} / \mathrm{L}$ ) on at least 2 different occasions with a normal FSH and $\mathrm{LH}$, and a $\mathrm{HbA1c}$ of less than $9 \%(<75 \mathrm{mmol} / \mathrm{mol})$ were recruited. Subjects were randomised either to $15 \mathrm{~g}$ soy protein alone (SP) (all isoflavones removed by serial alcohol washing ${ }^{9}$ ) per day or $15 \mathrm{~g}$ soy protein with $66 \mathrm{mg}$ of isoflavones (SPI) per day for 3 months.

Subjects were on stable medications for hypertension, hyperlipidemia and T2DM for at least 3 months prior to the study. Those with significant renal or hepatic impairment, receiving testosterone replacement, who were allergic to soy products, or who had received antibiotics 3 months prior to the study were excluded. Participants were instructed to maintain their level of physical activity throughout the study. Participants were required to avoid food products containing alcohol, soy, alcohol, mineral or vitamin supplementation, and any over-the-counter medications. Plasma isoflavone concentrations were measured at each visit to ensure adherence. All methods were performed in accordance with the relevant guidelines and regulations. All subjects gave their written informed consent. Ethical approval was given by East Yorkshire \& North Lincolnshire Research Ethics Committee, ref: 09/ H1304/45.

Study product. Bar containing $7.5 \mathrm{~g}$ of the isoflavone-free soy protein (SP) or $7.5 \mathrm{~g}$ isolated soy protein powder (Solcon F, Solbar Industries, Ashdod, Israel) with $33 \mathrm{mg}$ of isoflavones (Solgen 40, Solbar Industries Israel) (SPI) was consumed twice daily for 3 months. Essential Nutrition Ltd, Brough, UK performed randomization based on a computer generated randomization list.

Bone turn over markers. Plasma P1NP and $\beta C T X$ were measured using an electrochemiluminescent immunoassay (Roche Diagnostics, Lewes, UK). Inter/Intra assay coefficient of variation of plasma $\beta C T X$ were both $<4 \%$ between 0.2 and $1.5 \mu \mathrm{g} / \mathrm{L}$. The assay sensitivity was $0.01 \mu \mathrm{g} / \mathrm{L}$. Inter/Intra assay CV of plasma P1NP were both $<3 \%$ between $20-600 \mu \mathrm{g} / \mathrm{L}$. The assay sensitivity was $8 \mu \mathrm{g} / \mathrm{L}$.

LC-MS/MS was used to extract and analyse serum phytoestrogens ${ }^{10}$. The inter assay CVs were less than $7.4 \%$ for equol, less than $6.1 \%$ for genistein and less than $6.8 \%$ for daidzein between $0.5 \mathrm{ng} / \mathrm{mL}$ to $200 \mathrm{ng} / \mathrm{mL}$. The intra assay CVs were less than $8.0 \%$ for equol, less than $3.6 \%$ for genistein and less than $7.2 \%$ for daidzein between $0.5 \mathrm{ng} / \mathrm{mL}$ to $200 \mathrm{ng} / \mathrm{mL}$.

Statistical analysis. The sample size was initially calculated based on the aims of the primary study ${ }^{9}$. Based on a study using the same soy preparation on bone turnover markers involving post-menopausal women ${ }^{11}$, a post hoc power analysis for changes in $\beta$ CTX and P1NP using N-query software, for $90 \%$ power, 2-tailed with an alpha of 0.05 required 12 subjects per arm for $\beta C T X$ and 60 subjects per group for P1NP, including a 20\% dropout rate.

Baseline continuously distributed data is presented as median $\left(25^{\text {th }} / 75^{\text {th }}\right.$ centiles); categorical data by $\mathrm{n}(\%)$. Within-group differences (difference between 12 week values and baseline values) are shown for each treatment group separately by a mean and a standard deviation (SD). Between-group comparisons were performed using the independent sample t-test. A two-tailed $\mathrm{P}<0.05$ was considered to indicate statistical significance for all analysis. Bonferroni corrections were not applied ${ }^{12}$. STATA statistical computer package (StataCorp. 2013. Stata Statistical Software: Release 13. College Station, TX: StataCorp LP, USA) was used for statistical analysis.

\section{Results}

412 participants were screened and 200 with T2DM and low testosterone concentrations were recruited. 29 patients dropped out (14 patients SP group and 15 patients SPI group $)^{9}$. The baseline parameters of the two groups are given in Table 1 .

There was a $15 \%$ decrease in $\beta$ CTX with 3 months of SPI supplementation. There were no changes in P1NP with either SPI or SP supplementation (Table 2). The changes in $\beta$ CTX with SPI supplementation were significantly greater when compared to three months of SP supplementation.

There was a significant linear correlation between reduction in $\beta$ CTX in the SPI group with reduction in HOMA-IR $\left(\mathrm{r}^{2}=0.54 ; \mathrm{p}=0.02\right)$ and HbAlc $\left(\mathrm{r}^{2}=0.42 ; \mathrm{p}=0.04\right)$. There were no correlations between a reduction in $\beta$ CTX with changes in triglycerides $\left(r^{2}=0.10 ; p=0.48\right)$, hsCRP $\left(r^{2}=0.26 ; p=0.33\right), f T 4\left(r^{2}=0.10 ; p=0.69\right)$ or TSH $\left(\mathrm{r}^{2}=0.12 ; \mathrm{p}=0.72\right)$ concentrations in the SPI group. There was also no correlation between changes in $\beta C T X$ with SPI supplementation with changes in daidzein $\left(r^{2}=0.16 ; p=0.22\right)$, genistein $\left(r^{2}=0.13 ; p=0.54\right)$ and equol $\left(\mathrm{r}^{2}=0.20 ; \mathrm{p}=0.77\right)$ concentrations.

\section{Discussion}

In this study, there was a significant reduction in the bone resorption marker $\beta$ CTX after three months of combined soy protein and isoflavone supplementation in men with T2DM. The reduction in $\beta$ CTX was correlated with an improvement in glycemic control and insulin resistance suggesting the effect of soy in bone may be mainly through modifying insulin resistance.

Patients with T2DM have increased risk of fractures especially of hip ${ }^{1,2}$. In the Rotterdam Study, an increased fracture risk for nonvertebral fractures (hip and wrist) was described [HR 1.33 (1.00-1.77)] despite higher BMD ${ }^{13}$. In subset analysis, the increased fracture risk seemed to be restricted to treated T2DM [HR 1.69 (1.16-2.46)], with subjects with impaired glucose tolerance showing a reduced fracture risk. This decreased bone strength may develop as a consequence of insulin resistance associated with T2DM and of particular relevance with the finding here of the decrease in $\beta$ CTX associated with a decrease in insulin resistance. An inverse association of fasting insulin with periosteal circumference has been reported in healthy adolescents ${ }^{14,15}$, and insulin resistance correlated inversely with periosteal and endosteal circumference ${ }^{16,17}$. Other putative indirect mechanisms whereby 


\begin{tabular}{|l|l|l|}
\hline Parameters & $\begin{array}{l}\text { SP1 group } \\
(\mathbf{n}=100)\end{array}$ & $\begin{array}{l}\text { SP group } \\
(\mathbf{n}=100)\end{array}$ \\
\hline Age (years) & $52.0(50.0,55.0)$ & $52.0(50.0,55.0)$ \\
\hline Weight & $100.1(88.5,112.3)$ & $98(85.7,111.9)$ \\
\hline Body Mass Index $\left(\mathrm{kg} / \mathrm{m}^{2}\right)$ & $31.8(28.8,34.7)$ & $31.6(29.2,35.0)$ \\
\hline Duration of diabetes (years) & $7.3(4.2,8.8)$ & $7.9(4.4,9.1)$ \\
\hline HbA1c $(\mathrm{mmol} / \mathrm{mol})$ & $56(52,60)$ & $58(53,64)$ \\
\hline TSH $(\mathrm{mU} / \mathrm{L})$ & $1.6(1.2,2.4)$ & $1.6(1.2,2.5)$ \\
\hline fT4 $(\mathrm{pmol} / \mathrm{L})$ & $12.0(12.0,14.0)$ & $13.0(12.0,14.0)$ \\
\hline Fasting glucose $(\mathrm{mmol} / \mathrm{L})$ & $139.5(118.8,160.7)$ & $135.9(115.2$, \\
\hline Fasting insulin $(\mu \mathrm{IU} / \mathrm{mL})$ & $16.5(9.9,25.3)$ & $18.0(10.4,28.6)$ \\
\hline HOMA-IR & $5.6(3.6,9.0)$ & $6.2(3.8,9.7)$ \\
\hline hsCRP $(\mathrm{mg} / \mathrm{L})$ & $2.1(0.8,3.9)$ & $1.9(0.9,4.1)$ \\
\hline TC $(\mathrm{mmol} / \mathrm{L})$ & $3.9(3.4,4.6)$ & $3.8(3.4,4.5)$ \\
\hline LDL-C $(\mathrm{mmol} / \mathrm{L})$ & $2.0(1.7,2.9)$ & $2.0(1.6,2.7)$ \\
\hline HDL-C $(\mathrm{mmol} / \mathrm{L})$ & $1.1(0.9,1.3)$ & $1.0(0.9,1.2)$ \\
\hline Triglycerides $(\mathrm{mmol} / \mathrm{L})$ & $1.4(1.0,2.1)$ & $1.3(0.9,2.0)$ \\
\hline Daidzein $(\mathrm{ng} / \mathrm{mL})$ & $1.4(0.6,2.7)$ & $1.9(0.7,4.3)$ \\
\hline Genistein $(\mathrm{ng} / \mathrm{mL})$ & $2.6(0.7,5.7)$ & $2.9(1.3,7.2)$ \\
\hline Equol $(\mathrm{ng} / \mathrm{mL})$ & $0.1(0.1,0.1)$ & $0.1(0.1,0.1)$ \\
\hline
\end{tabular}

Table 1. Baseline parameters between the SPI and SP groups. SPI ( $15 \mathrm{~g}$ soy protein with $66 \mathrm{mg}$ of isoflavones); SP ( $15 \mathrm{~g}$ soy protein alone without any isoflavones) Values are provided as medians $\left(25^{\text {th }} / 75^{\text {th }}\right.$ centiles). To convert values for glucose to milligrams per deciliter, divide by 0.056 . To convert values for insulin to picomoles per liter, multiply by 6 . To convert values for cholesterol to milligrams per deciliter divide by 0.0259 . To convert values for triglycerides to milligrams per deciliter divide by 0.0113 . TC - Total cholesterol; LDL-C - LDL-cholesterol; HDL-C - HDL cholesterol; TG-Triglycerides; HbA1c - glycated hemoglobin; HOMA - Homeostasis model of assessment - insulin resistance; HsCRP - highly sensitive C-respire protein; FSH - follicle stimulating hormone; LH - Luteinizing hormone; SHBG - sex hormone binding globulin; TSH thyroid stimulating hormone; fT4 - free thyroxine; fT3 - free tri-iodo thyronine.

\begin{tabular}{|c|c|c|c|c|c|c|c|}
\hline \multirow[b]{3}{*}{ Parameters } & \multicolumn{3}{|l|}{ SPI } & \multicolumn{3}{|l|}{ SP } & \multirow{3}{*}{$\begin{array}{l}\text { Difference of } \\
\text { the difference } \\
\text { p value }\end{array}$} \\
\hline & Baseline & 3 months & p-value & Baseline & 3 months & p value & \\
\hline & Mean (SD) & Mean (SD) & (3 mo-baseline) & Mean (SD) & Mean (SD) & (3 mo-baseline) & \\
\hline \multicolumn{8}{|c|}{ Bone turn over markers } \\
\hline$\beta \mathrm{CTX}(\mu \mathrm{g} / \mathrm{L})$ & $0.22(0.09)$ & $0.19(0.08)$ & 0.04 & $0.22(0.10)$ & $0.22(0.11)$ & 0.89 & $<0.01$ \\
\hline $\mathrm{P} 1 \mathrm{NP}(\mu \mathrm{g} / \mathrm{L})$ & $31(12)$ & $32(11)$ & 0.66 & $33(13)$ & $33(12)$ & 0.352 & 0.322 \\
\hline
\end{tabular}

Table 2. Comparison between SPI and SP supplementation at end of study of bone turnover markers. Paired difference $=3$-months-baseline. Difference of the difference is an unpaired t-test of the paired differences. SPI ( $15 \mathrm{~g}$ soy protein with $66 \mathrm{mg}$ of isoflavones); SP (15g soy protein alone isoflavone free) BTM - bone turnover marker. $\beta C T X$ - collagen type 1 cross-linked Beta C-telopeptide. P1NP - propeptide of type I collagen.

insulin resistance may affect bone involve a suggested role of hyperinsulinemia in bone ageing ${ }^{18,19}$, reduced blood flow to the bone tissue adversely affecting bone remodeling ${ }^{19}$ and it has been shown that osteoblast-specific disruption of the insulin receptor leads to impaired osteoblast differentiation and reduced trabecular bone formation $^{20,21}$. Experimental studies indicated that similar to skeletal muscle, hepatic, and adipose tissue, insulin resistance can develop in bone tissue, and that this compromised insulin signaling is associated with decreased bone remodeling ${ }^{22}$. Hence improving insulin resistance through soy preparations with a combination of soy protein and isoflavone could potentially improve bone health as shown in this study.

The isoflavone concentrations used in the study preparation reflects the daily intake of Asian population consuming high soy diet or people consuming soy supplements of around 50-90 mg per day ${ }^{23,24}$. Epidemiological studies generally suggest a positive association between soy consumption and $\mathrm{BMD}^{25}$. Isoflavones are heterocyclic phenols found in various plant products including soy, the main constituents of which are genistein, daidzein and glycitein. They have a similar structure to 17 beta estradiol and have been shown to have biological activity exerting estrogen-like effects both in vitro and in vivo. Estrogen can increase BMD and has a protective effect on bones in females. In the present study, there was a mean $15 \%$ reduction in $\beta C T X$ suggesting beneficial effects on bones. These findings are similar to our previous observation in post-menopausal women using similar soy preparations ${ }^{11}$ in which there was a significant reduction in $\beta C T X$ after 6 months of SPI preparation compared to SP preparation ${ }^{11}$. Potent anti-resorptive agents such as bisphosphonates and denosumab, act by reducing bone turn over although to a greater magnitude ${ }^{26}$. Treatment with bisphosphonate reduce CTX by around $40-50 \%{ }^{27,28}$. 
The reduction of CTX by isoflavones compares well with dietary treatments ${ }^{11}$ and could possibly be used in combination with other anti-osteoporotic drug treatments.

In patients with T2DM circulating biochemical markers of bone formation are decreased ${ }^{29-31}$. In post-menopausal women using a similar soy preparation, changes in P1NP were more pronounced, with a significant decrease in P1NP after 6 months of SPI preparation ${ }^{11}$. In the current study, there were no significant changes in P1NP after 3 months of SPI supplementation that may be due to shorter duration of supplementation.

There were no correlation of changes in $\beta C T X$ with changes in plasma isoflavones including daidzein, genistein and equol suggesting that the effect of SPI on this bone turnover marker is not a direct effect. This lack of association could also be due to the fact that since the same dose was given to participants, their plasma isoflavones were raised to the same degree but the difference in response to the isoflavones could be due to unmeasured factors such as difference in genetic background and metabolism. There was no correlation of changes in $\beta C T X$ with changes in lipids or hsCRP, which is an inflammatory marker.

The strengths of this study include that a comparison with a confirmed isoflavone free preparation was undertaken and isoflavone measurement confirmed compliance. Although the study was not powered primarily to look at changes in bone turn over markers, based on another report of bone turnover markers ${ }^{11}$ this study had significant power to detect changes in those markers, accounting for drop outs.

In conclusion, combined soy protein and isoflavone supplementation for three months in men with T2DM significantly reduced the bone-resorption marker $\beta$ CTX that correlated with an improvement in glycemic control and insulin resistance, suggesting that the effect of soy protein with isoflavones in bone may be mediated through modifying insulin resistance.

\section{References}

1. Janghorbani, M., Van Dam, R. M., Willett, W. C. \& Hu, F. B. Systematic review of type 1 and type 2 diabetes mellitus and risk of fracture. American journal of epidemiology 166, 495-505, https://doi.org/10.1093/aje/kwm106 (2007).

2. Vestergaard, P. Discrepancies in bone mineral density and fracture risk in patients with type 1 and type 2 diabetes-a meta-analysis. Osteoporosis international: a journal established as result of cooperation between the European Foundation for Osteoporosis and the National Osteoporosis Foundation of the USA 18, 427-444, https://doi.org/10.1007/s00198-006-0253-4 (2007).

3. Leslie, W. D., Rubin, M. R., Schwartz, A. V. \& Kanis, J. A. Type 2 diabetes and bone. Journal of bone and mineral research: the official journal of the American Society for Bone and Mineral Research 27, 2231-2237, https://doi.org/10.1002/jbmr.1759 (2012).

4. van den Beld, A. W., de Jong, F. H., Grobbee, D. E., Pols, H. A. \& Lamberts, S. W. Measures of bioavailable serum testosterone and estradiol and their relationships with muscle strength, bone density, and body composition in elderly men. J Clin Endocrinol Metab 85, 3276-3282, https://doi.org/10.1210/jcem.85.9.6825 (2000).

5. Dhindsa, S. et al. The effects of hypogonadism on body composition and bone mineral density in type 2 diabetic patients. Diabetes Care 30, 1860-1861, https://doi.org/10.2337/dc07-0337 (2007).

6. Xiao, C. W. Health Effects of Soy Protein and Isoflavones in Humans. The Journal of nutrition 138, 1244S-1249S (2008).

7. Jayagopal, V. et al. Beneficial effects of soy phytoestrogen intake in postmenopausal women with type 2 diabetes. Diabetes Care 25 , 1709-1714 (2002).

8. Colleluori, G. et al. Hypogonadal men with type 2 diabetes mellitus have smaller bone size and lower bone turnover. Bone 99, 14-19, https://doi.org/10.1016/j.bone.2017.03.039 (2017).

9. Sathyapalan, T. et al. Effect of Soy in Men With Type 2 Diabetes Mellitus and Subclinical Hypogonadism: A Randomized Controlled Study. The Journal of clinical endocrinology and metabolism 102, 425-433, https://doi.org/10.1210/jc.2016-2875 (2017).

10. Grace, P. B., Mistry, N. S., Carter, M. H., Leathem, A. J. \& Teale, P. High throughput quantification of phytoestrogens in human urine and serum using liquid chromatography/tandem mass spectrometry (LC-MS/MS). Journal of chromatography. B, Analytical technologies in the biomedical and life sciences 853, 138-146, https://doi.org/10.1016/j.jchromb.2007.03.011 (2007).

11. Sathyapalan, T. et al. Soy Reduces Bone Turnover Markers in Women During Early Menopause: A Randomized Controlled Trial. Journal of bone and mineral research: the official journal of the American Society for Bone and Mineral Research 32, 157-164, https:// doi.org/10.1002/jbmr.2927 (2017).

12. Rothman, K. J. No adjustments are needed for multiple comparisons. Epidemiology 1, 43-46 (1990).

13. de, L. II et al. Bone mineral density and fracture risk in type-2 diabetes mellitus: the Rotterdam Study. Osteoporos Int 16, 1713-1720, https://doi.org/10.1007/s00198-005-1909-1 (2005).

14. Lawlor, D. A., Sattar, N., Sayers, A. \& Tobias, J. H. The association of fasting insulin, glucose, and lipids with bone mass in adolescents: findings from a cross-sectional study. The Journal of clinical endocrinology and metabolism 97, 2068-2076, https://doi. org/10.1210/jc.2011-2721 (2012).

15. Sayers, A., Lawlor, D. A., Sattar, N. \& Tobias, J. H. The association between insulin levels and cortical bone: findings from a crosssectional analysis of pQCT parameters in adolescents. Journal of bone and mineral research: the official journal of the American Society for Bone and Mineral Research 27, 610-618, https://doi.org/10.1002/jbmr.1467 (2012).

16. Shanbhogue, V. V., Finkelstein, J. S., Bouxsein, M. L. \& Yu, E. W. Association Between Insulin Resistance and Bone Structure in Nondiabetic Postmenopausal Women. The Journal of clinical endocrinology and metabolism 101, 3114-3122, https://doi.org/10.1210/ jc.2016-1726 (2016).

17. Verroken, C., Zmierczak, H. G., Goemaere, S., Kaufman, J. M. \& Lapauw, B. Insulin Resistance Is Associated with Smaller Cortical Bone Size in Non-Diabetic Men at the Age of Peak Bone Mass. The Journal of clinical endocrinology and metabolism, jc20163609, https://doi.org/10.1210/jc.2016-3609 (2016).

18. Lee, H. S., Shim, Y. S., Jeong, H. R., Kwon, E. B. \& Hwang, J. S. The Association between Bone Age Advancement and Insulin Resistance in Prepubertal Obese Children. Exp Clin Endocrinol Diabetes 123, 604-607, https://doi.org/10.1055/s-0035-1559795 (2015).

19. Hinton, P. S. Role of reduced insulin-stimulated bone blood flow in the pathogenesis of metabolic insulin resistance and diabetic bone fragility. Medical hypotheses 93, 81-86, https://doi.org/10.1016/j.mehy.2016.05.008 (2016).

20. Fulzele, K. et al. Insulin receptor signaling in osteoblasts regulates postnatal bone acquisition and body composition. Cell 142, 309-319, https://doi.org/10.1016/j.cell.2010.06.002 (2010).

21. Ferron, M. et al. Insulin signaling in osteoblasts integrates bone remodeling and energy metabolism. Cell 142, 296-308, https://doi. org/10.1016/j.cell.2010.06.003 (2010).

22. Wei, J. et al. Bone-specific insulin resistance disrupts whole-body glucose homeostasis via decreased osteocalcin activation. J Clin Invest 124, 1-13, https://doi.org/10.1172/JCI72323 (2014).

23. de Kleijn, M. J. et al. Intake of dietary phytoestrogens is low in postmenopausal women in the United States: the Framingham study(1-4). The Journal of nutrition 131, 1826-1832 (2001).

24. Strom, S. S. et al. Phytoestrogen intake and prostate cancer: a case-control study using a new database. Nutrition and cancer 33, 20-25, https://doi.org/10.1080/01635589909514743 (1999). 
25. Sebastian, A. I. Protein, and bone. The American journal of clinical nutrition 81, 733-735 (2005).

26. Brown, J. P. et al. Comparison of the Effect of Denosumab and Alendronate on BMD and Biochemical Markers of Bone Turnover in Postmenopausal Women With Low Bone Mass: A Randomized, Blinded, Phase 3 Trial. J. Bone Miner. Res. 24, 153-161, https://doi. org/10.1359/jbmr.0809010 (2009).

27. van den Bergh, J. P. et al. Comparing tolerability and efficacy of generic versus brand alendronate: a randomized clinical study in postmenopausal women with a recent fracture. PloS one 8, e78153, https://doi.org/10.1371/journal.pone.0078153 (2013).

28. Delmas, P. D. et al. Effects of yearly zoledronic acid $5 \mathrm{mg}$ on bone turnover markers and relation of PINP with fracture reduction in postmenopausal women with osteoporosis. Journal of bone and mineral research: the official journal of the American Society for Bone and Mineral Research 24, 1544-1551, https://doi.org/10.1359/jbmr.090310 (2009).

29. Dobnig, H. et al. Type 2 diabetes mellitus in nursing home patients: effects on bone turnover, bone mass, and fracture risk. J Clin Endocrinol Metab 91, 3355-3363, https://doi.org/10.1210/jc.2006-0460 (2006).

30. Ardawi, M. S. et al. Increased serum sclerostin and decreased serum IGF-1 are associated with vertebral fractures among postmenopausal women with type-2 diabetes. Bone 56, 355-362, https://doi.org/10.1016/j.bone.2013.06.029 (2013).

31. Gaudio, A. et al. Sclerostin levels associated with inhibition of the Wnt/beta-catenin signaling and reduced bone turnover in type 2 diabetes mellitus. J Clin Endocrinol Metab 97, 3744-3750, https://doi.org/10.1210/jc.2012-1901 (2012).

\section{Acknowledgements}

This study was supported by the Food Standards Agency, United Kingdom (T01057). The sponsors did not influence the study design; the collection, analysis, and interpretation of data; the writing of the report; and the decision to submit the paper for publication. Any views or opinions expressed are solely those of the authors and do not necessarily represent those of the FSA.

\section{Author Contributions}

S.L.A., E.S.K. and T.S. conceived the study, all authors were involved in reviewing the proposal and conducting the study, A.S.R. involved in statistical analysis, S.B. performed the testosterone assays, W.D.F. the bone marker assays, T.S. drafted the first draft, all authors reviewed the manuscript and had access to all trials data. T.S. and S.L.A. are the guarantors for this article. All data generated or analysed during this study are included in this published article.

\section{Additional Information}

Competing Interests: The authors declare that they have no competing interests.

Publisher's note: Springer Nature remains neutral with regard to jurisdictional claims in published maps and institutional affiliations.

(c) (i) Open Access This article is licensed under a Creative Commons Attribution 4.0 International License, which permits use, sharing, adaptation, distribution and reproduction in any medium or format, as long as you give appropriate credit to the original author(s) and the source, provide a link to the Creative Commons license, and indicate if changes were made. The images or other third party material in this article are included in the article's Creative Commons license, unless indicated otherwise in a credit line to the material. If material is not included in the article's Creative Commons license and your intended use is not permitted by statutory regulation or exceeds the permitted use, you will need to obtain permission directly from the copyright holder. To view a copy of this license, visit http://creativecommons.org/licenses/by/4.0/.

(c) The Author(s) 2017 